\title{
La inmigración como problema: un análisis de las prácticas discursivas de la población autóctona
}

\author{
Antonio Morell Blanch \\ Universitat de Lleida. Departament d'Economia Aplicada \\ Campus de Cappont. Carrer de Jaume II, 73. 25001 Lleida \\ antonio.morell@econap.udl.es
}

\section{Resumen}

Las prácticas discursivas son la base de las construcciones simbólicas de los individuos, y mediante su análisis podemos acceder a la comprensión que ellos tienen de la realidad. $\mathrm{O}$, dicho en otras palabras, el estudio de las estructuras ideológicas configuradoras de los discursos del racismo son accesibles a través de un análisis sociológico del lenguaje. Proponemos, por tanto, un análisis que se ocupe de las configuraciones discursivas dominantes en la representación social de los inmigrantes, con el fin de detectar los ejes estructuradores de las actitudes de aceptación o rechazo que su presencia genera en la población autóctona, con el fin de lograr una mejor comprensión de la génesis de los discursos que sustentan la visión de «la inmigración como problema».

Palabras clave: identidad, inmigración, Internet, racismo.

Abstract. The immigration as a problem: an analysis of the speech practices of the native population

The study of the ideological structures that shape racism, is accessible through the sociological analysis of the language. In this article we present an analysis of the dominant discursive configurations in the social representation of the immigrants, with the purpose of establishing the structural axes of the acceptance or rejection attitudes that its presence generates in the native population.

Key words: identity, immigration, Internet, racism.

\section{Sumario}

1. Introducción 4. A modo de conclusión

2. El inmigrante como amenaza Bibliografía

3. El inmigrante como competidor 


\section{Introducción}

Las prácticas discursivas son la base de las construcciones simbólicas de los individuos, y mediante su análisis podemos acceder a la comprensión que los individuos tienen de la realidad. $\mathrm{O}$, dicho en otras palabras, el estudio de las estructuras ideológicas configuradoras de los discursos del racismo son accesibles a través de un análisis sociológico del lenguaje. Proponemos, por tanto, realizar un análisis que se ocupe de las configuraciones discursivas dominantes en la representación social de los inmigrantes, con el fin de detectar los ejes estructuradores de las actitudes de aceptación o rechazo que su presencia genera en la población autóctona y, con ello, lograr una mejor comprensión de la génesis de los discursos que sustentan la visión de «la inmigración como problema».

Para ello recurrimos a la información que proporcionan los «foros de discusión» en Internet, pues, en nuestra opinión, resuelven satisfactoriamente ciertas limitaciones que se detectan en los grupos de discusión creados al efecto de una determinada investigación: la premisa de «anonimato de las intervenciones» elimina cualquier tipo de restricción o condicionante social, y permite superar la resistencia a expresar opiniones que podrían silenciarse ante la presencia de un observador por considerarse «moralmente incorrectas» o de algún modo «censurables». De este modo, se evita que la presencia del observador modifique los cursos de acción y las motivaciones de los participantes.

Por otro lado, resulta más que discutible aducir la irrelevancia de las opiniones al considerar que los participantes tienden a crear personajes, a inventarlos. A menudo se señala que la interacción en entornos cibersociales "permiten el desarrollo de narrativas del ego diferentes a las que se producen en la vida real», pero que la identidad de los participantes sea real o ficticia significa que se corresponde o no con la identidad social pública del individuo, no que sea falsa ${ }^{1}$. Como recuerda Turkle (1997), «el ciberespacio proporciona oportunidades para jugar con aspectos de uno mismo que no son totalmente ajenos a uno mismo, pero que pueden estar inhibidos en la vida real». Es decir, «el personaje, salvo excepciones extremas, no puede dejar de ser jamás uno mismo, a la vez que nunca puede llegar a serlo del todo» (Mayans, 2002:192-197). Por ello, también la representación del personaje que realiza se mueve entre lo falso y lo sincero, sin poder llegar a ninguno de los dos extremos.

El trabajo de campo se ha realizado a partir las conversaciones mantenidas en los «foros de discusión» sobre inmigración que proporcionan los grandes portales en lengua castellana (Yahoo, Wanadoo, Terra, Tiscali, Ya.com, etc.) entre los días 1 de enero y 30 de abril de 2003. Para ello, ha sido preciso identificar los foros que tienen como temática principal la inmigración y aislar los

1. «Se puede sentir animadversión o rechazo ante la presencia de personas extranjeras (o de etnia diferente) y, en cambio, no exteriorizar dicho sentimiento. Depende, principalmente, de la licitud que el grupo social de referencia atribuya a la manifestación racista» (Valles y otros, 1999: 79). 
ubicados en servidores españoles. En una fase posterior, hemos descartado los que tan sólo presentaban intervenciones esporádicas para centrarnos en los más activos y dinámicos. El resultado ha sido la selección de cinco foros ubicados en los portales Terra, Tiscali y Ya.com. Las opiniones han sido clasificadas en función de la temática tratada y de los clichés que presentaban una mayor frecuencia. Las intervenciones se reproducen en su estado original, con el fin de reflejar mejor las opiniones de los participantes, sin embargo, se omiten los insultos y/o las frases despectivas hacia el colectivo inmigrante y se corrigen ciertos errores ortográficos (falta de acentos, etc.) y de transcripción evidentes, con el fin de facilitar su lectura. Ello no modifica en modo alguno el significado de las intervenciones, simplemente supone contemplar que en este medio «la estructura de las conversaciones está pautada según unas reglas que tienen por referente el de las conversaciones orales, pero que no reproduce de forma exacta» (Mayans, 2002:112).

La información recogida se ha sometido a operaciones de segmentación y codificación. Con el fin de facilitar la interpretación y el análisis de los datos, una vez constatada la presencia de elementos comunes que resultarían excesivamente repetitivos en un análisis individual de las categorías identificadas, se ha procedido a conectar aquéllas que mantienen una afinidad temática, lo que ha dado lugar a «núcleos» $\mathrm{o}$ "megacategorías» alrededor de las cuales se agrupa la mayoría de las consideradas inicialmente. El resultado ha sido la existencia de cuatro grandes núcleos que, a su vez, remiten a dos grandes visiones de la inmigración, esto es, «el inmigrante como amenaza» y el «inmigrante como competidor», que finalmente han servido para articular nuestro análisis.

La primera de ellas, «el inmigrante como amenaza», remite al temor de la población por la incidencia que la inmigración «masiva» pueda tener en la «identidad» y el «estilo de vida» autóctono (las visiones más extremas remiten a la idea de «invasión cultural»). El miedo al inmigrante se complementa con la idea de que el incremento de la inseguridad ciudadana y la delincuencia es el resultado de una inmigración incontrolada. Paralelamente, se presenta la visión del inmigrante como un "competidor» por los puestos de trabajo y por los recursos de bienestar, lo que repercutiría negativamente en el nivel de vida de la población autóctona. Estos son los ejes articuladores de las prácticas discursivas de la población autóctona que sustentan la visión del «inmigrante como problema», tal como queda sintetizado en el gráfico 1.

\section{El inmigrante como amenaza}

España se encuentra sometida a una presión migratoria sin precedentes que desborda cualquier posibilidad razonable de integración. Esta idea sintetiza los argumentos de quienes ven y presentan la inmigración como un peligro para la identidad cultural autóctona. Su preocupación fundamental es preservar los rasgos identitarios característicos de nuestra cultura, que estarían en peligro por la entrada «masiva» de inmigrantes procedentes de universos culturales 


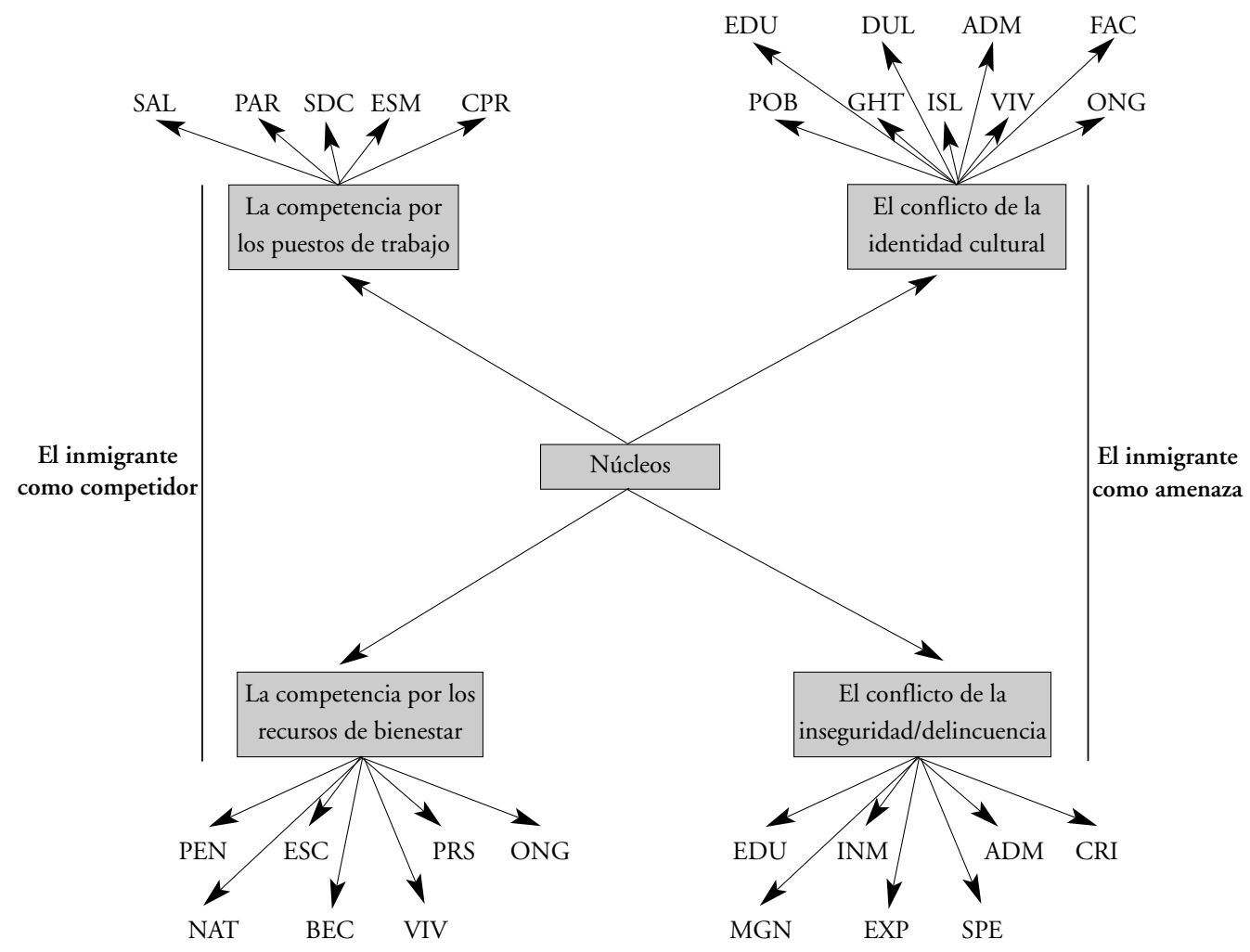

Gráfico 1.

distintos al nuestro, muchos de ellos inmigrantes irregulares, lo que impide conocer el volumen real de población extranjera residente en nuestro país, pero que en cualquier caso se presenta como muy superior al que registran las estadísticas oficiales.

¿Cifras? Mira, creo que lo que hay que hacer es darse una vuelta por Madrid o Barcelona y observar la ciudad. [f1/2.04]

Yo paso de las estadísticas. Prefiero observar la realidad que me rodea y ciertamente me preocupan temas como la inseguridad ciudadana o mantener mi calidad de vida. Con la llegada de tantos ilegales, está claro que los españoles salimos perdiendo. [f1/2.07]

En general, se acepta que el Estado español presenta una gran diversidad cultural, pero se trata de culturas propias, autóctonas, que comparten deter- 
minados valores, lo que facilita su convivencia. El problema surge al plantear los límites de la diversidad, es decir, la presencia en nuestro territorio de personas con culturas que se señalan como "opuestas y rivales» a la nuestra y, por tanto, culturas que transmiten valores que dificultan la integración de quienes las sustentan en nuestra sociedad:

La nación española siempre ha sido, es y será un gran crisol de culturas. Cuando hablamos de España no hablamos del pueblo español, sino del pueblo castellano, el pueblo gallego, el pueblo vasco, el catalán, el andaluz, etc. Cada pueblo tiene su cultura, sus costumbres y su gastronomía típica, incluso hasta su propia lengua. Pero estas diferencias culturales son muy pequeñas y en cualquier caso son fácilmente integrables dentro de un mismo territorio y de fácil adaptación, comprensión y conversión de una a otra.

Hasta con los pueblos hispanoamericanos puede ser igual [...] puesto que en su momento fueron colonizados por los castellanos, y aunque el tiempo haya creado algunas diferencias, por lo general se parece bastante a la cultura castellana, a veces con influencia indígena.

Con los demás pueblos europeos también hay diferencias, pero, igual que entre los pueblos españoles, las diferencias no son muy grandes y por lo tanto no hay problemas entre ellos.

Pero el problema viene cuando en España se instalan culturas completamente distintas a la nuestra, incluso opuestas y rivales. [f1/2.01]

Como reconoce Calvo (1990), existe una escala de los otros, de tal manera que la sensación de invasión hace referencia sólo a una parte de los extranjeros. A medida que existe una mayor distancia del grupo respecto de la cultura occidental, la raza blanca y la religión cristiana, la tolerancia disminuye. Los discursos de la población autóctona reflejan esta tendencia: los estereotipos de signo positivo y negativo varían en función de la distancia cultural percibida. Cuando ésta aumenta, más probabilidades existen de que se les presente como personas carentes de las más elementales normas de convivencia:

Yo nunca he sido racista, pero me veo obligada a convivir con personas que no tienen reglas de convivencia, ni educación, ni ganas de integrarse ni adaptarse para nada desde el respeto, en el país en el que viven. Y sinceramente, estoy harta de ellos [...] Yo invito al que quiera contradecirme y me llame xenófoba que pruebe a convivir un mes con ellos. Es imposible. [f1/3.05]

De este modo, la cultura sustituye a la raza como elemento discriminante de las actitudes xenófobas: no se señala la existencia de razas superiores e inferiores (racismo moderno), sino la existencia de universos culturales incompatibles (racismo posmoderno). En cualquier caso, los argumentos racistas clásicos no quedan totalmente eliminados de los discursos, si bien su presencia es minoritaria:

Y las preguntas que has propuesto sobre por qué los del Tercer Mundo siempre están en la miseria, pues [...] es debido al C.I. de su raza, la raza negra es el peor C.I. del mundo debido a que su cerebro es más pequeño que la raza 
blanca y está comprobado por los médicos estadounidenses mediante rayos $\mathrm{X}$ [...] nos están engañando y dicen que todos somos iguales, pues no es así, más bien nosotros somos distintos a otras razas en psicológicamente, en físicamente, en los rasgos faciales, etc. [f1/2.04]

Como hemos dicho, el racismo posmoderno pone el énfasis en la dificultad de entablar un diálogo igualitario entre las culturas con el fin de establecer normas comunes de convivencia. Por tanto, los otros no son todos los extranjeros, sino aquéllos que poseen unos rasgos étnicos y/o unas características socioculturales que se jerarquizan como «inferiores» (de este modo, el racismo se configura como una relación social de dominación) y se señalan como intrínsecamente distintas (incompatibles) a las nuestras. Además, en la medida que los rasgos morales se transmiten socialmente en función de los referentes culturales del grupo, el discurso omite referencias a individuos (las referencias a atributos personales resultan irrelevantes) para centrase en los colectivos. De este modo, la «tesis de la incompatibilidad cultural» sustenta la base de los nuevos discursos del racismo.

Me gusta saber que en el mundo hay una gran diversidad de culturas y costumbres, es muy bonito pero cuando están en su territorio. Muchas culturas en un mismo país siempre causan problemas. [f1/3.05]

Para Flecha (2001: 89), el racismo posmoderno «rechaza los presupuestos etnocentristas del racismo moderno argumentando que las culturas no son inferiores o superiores», pero «niega las posibilidades de diálogo entre culturas diferentes con el objetivo de establecer normas comunes para la convivencia en territorios compartidos». De este modo, se proclama que estamos ante un problema de convivencia y, con ello, se rechaza que estemos ante un problema de racismo o xenofobia, términos tabú que no aceptan ni quienes en sus intervenciones muestran posturas abiertamente segregadoras:

Te repito que a mí lo de la raza no me importa, pero quiero una España española, donde vivamos lo mejor posible y ya esta. [f1/3.06]

En cualquier caso, la respuesta a quiénes son los extranjeros, esto es, quiénes ponen en peligro nuestra identidad cultural, no es unánime: determinados sectores de población consideran que los ciudadanos de países miembros de la Unión Europea, además de disponer de un marco legal que les permite fijar libremente su residencia, comparten una cultura similar a la nuestra, por lo que su presencia, aunque llegara a ser masiva, en ningún caso puede constituir un peligro:

Vamos a ver si te enteras de que no es lo mismo un inmigrante alemán, francés, ingles, etc. que uno sudaca o moro, aunque sean igual de pobres, igual de negros, igual de lo que tu quieras. Uno será europeo y el otro no, uno será ciudadano comunitario y el otro no. [f1/3.07] 
Sin embargo, esta opinión no es unánimemente compartida y no faltan quienes los incluyen en el grupo de los «invasores». En este sentido, cabe recordar a Gallisot (1985) cuando señala que el racismo es la naturalización de la nacionalidad:

Has dicho que quieres que España sea española. Yo pregunto cómo se reconcilia eso con abogar por la expulsión de personas culturalmente más próximas a nosotros (por ejemplo, los sudacas) mientras al mismo tiempo se acepta sin problemas la «invasión» alemana o inglesa. [f1/3.11]

Las referencias al colectivo latinoamericano resultan particularmente sugerentes, pues encontramos posiciones enfrentadas entre quienes los consideran «invasores» y quienes resaltan la existencia de afinidades culturales y consideran que su integración en la sociedad española debe resultar sencilla. Sin embargo, el discurso racista muestra un argumento circular de imposible resolución. El recurso a rasgos físicobiológicos o a elementos culturales es secundario, se utiliza con el fin de encontrar elementos distintivos que permitan señalar al otro, al que es distinto, al que no pertenece a la comunidad. Con ello no se dan cuenta de que quien ha cambiado es la propia comunidad, de que los rasgos identitarios autóctonos que pretenden preservar en realidad no existen: no son más que una ficción sobre la que construyen sus propios esquemas comprensivos de la realidad. En un mundo globalizado, en el que los flujos migratorios adquieren mayor fluidez, señalar al otro resulta cada vez más difícil. Los rasgos identitarios se difuminan, y la respuesta a la pregunta de quiénes somos nosotros y quiénes son ellos cada vez es más difícil de responder. Veamos la siguiente conversación mantenida en uno de los foros:

Participante 1: Más de 1 millón de latinoamericanos serán españoles. Eso sí, serán españoles por la cara. [f1/1.27]

Participante 2: Soy venezolana nacionalizada española, y no soy española «por la cara» como tu dices, soy hija de española, así que soy española PORQUE ME CORRESPONDE POR DERECHO, y si no te gusta te aguantas. [f1/2.10]

Participante 3: Lógico, como vienes del Tercer Mundo, no te enteras, además intentas defender tus intereses, para mi eres una INVASORA y una OKUPA, por mucho documento que te hayan regalado. Ser español es un sentimiento, son generaciones ayudando a levantarlo, generaciones pagando impuestos, quererlo, mimarlo, etc., etc., etc., y tú lo único que has aportado es aprovecharte de todo esto, por lo tanto para mi eres una INVASORA. [f1/2.16]

La referencia al nivel de desarrollo socioeconómico del país de origen («como vienes del Tercer Mundo...») se utiliza para señalar la inferioridad del inmigrante ("...no te enteras»). Pero, además, el discurso racista considera que la inferioridad derivada de los atributos socioculturales del inmigrante es (prácticamente) permanente y no modificable en lo fundamental. De este modo, 
el «supuesto esencialista» ${ }^{2}$ (las culturas son universos cerrados y, por tanto, no modificables en sus rasgos fundamentales) complementa la tesis de la «incompatibilidad cultural», que, como hemos visto, sostiene la existencia de culturas incompatibles cuya coexistencia pacífica resulta inviable. Por tanto, el discurso xenófobo sólo plantea dos posibles soluciones: la asimilación (renuncia de los rasgos culturales originarios del inmigrante) o la segregación absoluta, con el fin de evitar que ambas culturas entren en contacto y se desencadene el conflicto.

El ejemplo más paradigmático lo encontramos en los rasgos culturales atribuidos al mundo islámico. Opuesto a la cultura occidental ilustrada y tolerante, es presentado como irracional, fanático, peligroso, violento, etc. La siguiente intervención es ilustrativa del miedo que origina su presencia en nuestro territorio, y en ella aparecen la mayoría de los tópicos que el imaginario popular atribuye a este colectivo:

La cultura musulmana es absolutamente opuesta a Occidente y nos considera sus enemigos. Además, es completamente incompatible una cultura que discrimina completamente a la mujer con la cultura europea que promueve la igualdad; una cultura que promueve la democracia con otra que promueve la monarquía del rey árabe; una cultura que promueve el Estado laico y la libertad religiosa con otra que manda que el Estado se rija por las leyes del islam que éste sea obligatorio.

También es fácil darse cuenta de lo que va a pasar: Mientras nosotros promovemos la libertad religiosa y toleramos a los musulmanes su libertad de religión, ellos no nos toleran a nosotros y creen que tienen que islamizarnos porque creen que su religión es la autentica verdad. DE AHI LOS PROBLEMAS QUE CAUSA EL TERRORISMO POR INTEGRISMO ISLÁMICO, QUE NO PASA CON NINGUNA OTRA RELIGION. Con lo cual, nuestro respeto hacia su cultura al final se volverá contra nosotros y Europa será árabe; además, ellos mismos dicen que España es Al-Andalus y que les pertenece, así que ya veremos qué ocurre cuando los musulmanes sean mayoría: ES UNA INVASIÓN SILENCIOSA. [f1/2.01]

En cualquier caso, los argumentos que insisten en la incompatibilidad cultural de las minorías étnicas no son exclusivos de los foros de discusión. En este sentido, por ejemplo, y si bien referido a una cuestión particular, cabe destacar la tesis de Donati (2002), quien considera que el mayor obstáculo del Welfare State se halla en los «conflictos de identidad cultural», esto es, entre culturas que interpretan de manera diferente el bienestar. La autora se pregunta: ¿qué hacer con las minorías culturales que no aceptan un régimen de tipo inclusivo y uniformizante propio de Welfare State? Así, una vez más, se

2. «La cultura de estos grupos (como sustancia de la etnia) es interpretada en un sentido claramente reificado. Esto lleva a pensar en las culturas como algo más que creaciones humanas, algo sobre lo que los otros, objetos culturales, no tienen ningún poder ni responsabilidad y que existe sobre ellos como un destino inevitable» (Samper, 2003: 3). 
plantea la dificultad de integración de ciertos colectivos de inmigrantes como un problema cultural, esto es, la coexistencia de culturas opuestas e incompatibles dificulta, cuando no impide, la convivencia de los inmigrantes con la población autóctona. Así lo afirma Sartori (2001) en su popular obra La sociedad multiétnica, cuando señala la existencia de inmigrantes inintegrables.

La tesis de que $s u$ cultura les impone valores, instituciones y prácticas incompatibles con las autóctonas constituye, en nuestra opinión, un grave error, pues ignora la dimensión dinámica y dialéctica de las culturas. Los procesos de diferenciación cultural deben considerarse estrategias adaptativas, lo que implica dejar de considerar la "cultura anfitriona» como el paradigma en el que deben desaparecer las «alógenas». Resulta imposible que un proceso de interacción social afecte sólo a una de las partes: no podemos pretender que la cultura autóctona se incorpore a la alógena sin que aquélla, a la vez, quede modificada. Propugnar lo contrario, más que una tesis —indica Lucas, (2002) —, es una propuesta ideológica que desemboca en esencialismo cultural. Terrén (2002: 49) pone de manifiesto el esencialismo en que ha caído buena parte de la investigación de tipo culturalista al ignorar que la identidad en el mundo moderno «es un juego abierto, complejo y sin fin, algo siempre en construcción». El esencialismo, en suma, comporta una visión cerrada de la cultura y la comunidad e impide reconocer muchos de los fenómenos asociados al carácter híbrido de la vida.

En síntesis, el término racismo ya no designa exclusivamente comportamientos discriminatorios basados en un referente físico-biológico. El racismo posmoderno no remite a razas, sino a culturas, y predica la segregación y expulsión de los otros bajo el pretexto de la incompatibilidad cultural: se considera que las identidades del grupo están predeterminadas y son inamovibles, y que las fronteras sociales que los separa son inalterables. Así pues, el «miedo a la invasión» ya no remite, salvo en contadas ocasiones, a la hipotética necesidad de preservar la "pureza de la raza». El termino racismo y las connotaciones negativas que a él se asocian están demasiado interiorizadas para que, también salvo excepciones, las personas acepten autoclasificarse como tales ${ }^{3}$. No se trata, pues, de preservar la superioridad de una raza, sino de preservar la superioridad de un modelo cultural que ha permitido acceder a mayores cotas de progreso, prosperidad y bienestar ${ }^{4}$. De este modo, las actitudes racistas se nutren del miedo a que la llegada masiva de inmigrantes («invasión») genere un proceso de impregnación cultural que llegue a modificar substancialmente los valores básicos sobre los que se funda la sociedad europea occidental,

3. «En las sociedades actuales avanzadas sólo determinadas minorías bien identificadas manifiestan de forma abierta actitudes racistas. La mayoría rechaza el racismo, si bien sólo en el plano manifiesto, ya que en el plano latente sigue aceptándolo» (Morales y Páez, 1996: 12).

4. "Atribuir a todas las culturas "igual valor" equivale a adoptar un relativismo absoluto que destruye la noción misma de valor. Si todo vale, nada vale: el valor pierde todo valor. Cualquier cosa vale, para cada uno de nosotros, porque su contraria "no vale". Y si no es así, entonces no estamos hablando de valores» (Sartori, 2001: 79-80). 
esto es, el peligro de que se llegue a quebrar el proceso ilustrado de la modernidad. Así, se enfrenta una supuesta cultura de la tolerancia a una supuesta cultura de la intransigencia o, dicho en otros términos, se enfrenta civilización a barbarie. Y descartada la posibilidad de convivencia (dado que los universos culturales de unos y otros son cerrados e incompatibles) las alternativas que quedan son escasas:

INMIGRANTES: Ni legales ni ilegales, ¡TODOS FUERA! [f1/3.05]

\section{¿Todos?}

Yo no creo que todos los extranjeros fuera, hay mucha diferencia entre los inmigrantes, yo he estado con gente hispana y de color, por no decir "negros", y musulmanes y hay mucha diferencia. La diferencia entre unos y otros no es el color, es la religión y la cultura. [f1/3.10]

$\mathrm{Si}$, como se afirma en el párrafo anterior, se acepta que las dificultades de integración no derivan de la raza sino de la cultura, de ello se deduce que la única integración posible pasa por modificar su estilo de vida con el fin de adaptarlo al de los autóctonos o, dicho en otras palabras, la «integración» que se propugna consiste en adoptar las costumbres españolas con el fin de «ser avistado como uno de nosotros». De este modo, la integración pasa por la invisibilidad, por la ocultación de los rasgos identitarios distintivos de los inmigrantes, cuanto menos cuando se actúa en el ámbito de lo público, permitiendo la manifestación de ciertas expresiones culturales alógenas cuando se circunscriben a la esfera de lo privado. Así lo propugna el presidente del Foro para la Integración Social de los Inmigrantes, Mikel Azurmendi (2001: 14): «De la misma manera que aprender español es un acto de voluntad de integración por parte del inmigrante, hacerse con costumbres españolas, cuando se interactúa en público, es otro dispositivo eficaz para acelerar el proceso de ser avistado como uno más de nosotros». Similares argumentos reproducen los participantes en los foros:

Los inmigrantes de otras culturas serán respetados siempre que ellos se españolicen y no se impongan ante los convecinos. [f2/3.23]

Si un inmigrante viene a un país $\mathrm{X}$ donde ya funciona de una forma $\mathrm{Y}$ PARA TODOS, no es tan difícil decir «voy a ser como ellos», aunque les cueste lo van a conseguir... [f1/3.12]

Pero, ¿por qué la presencia de inmigrantes produce rechazo? ¿Cuáles son los atributos culturales que el discurso racista atribuye a los distintos colectivos de inmigrantes? ¿En qué se concreta el miedo a la impregnación ideológica de nuestro universo cultural? En la línea de lo que señalan otros estudios precedentes (Colectivo IOÉ, 1994; Solé, 1995; etc.), existe un rasgo común que se asigna a todos los inmigrantes procedentes del Tercer Mundo, a partir del cual 
son configurados como diferentes: ellos son atrasados, nosotros no. Son subdesarrollados económicamente, pero también social y culturalmente.

[...] están más paleodesarrollados que nosotros. Que hace años nosotros lo hacíamos, pues vale. También quemábamos gatos negros, brujas, maltratábamos a los animales hasta el punto de no tener el más mínimo sentimentalismo con ellos, simplemente viéndolos como meras herramientas de trabajo, apalizábamos a nuestros hijos, y un sinfín de comportamientos que antes eran normales y aceptados y que ahora han cambiado. Y ELLOS AUN LOS LLEVAN y no sé si hacen esfuerzos por cambiarlos, pero al menos conseguirlo no lo están consiguiendo. En pocas palabras, siguen con su forma de vida, y esa forma de vida es la que les lleva a la oscuridad, y mi miedo, y el de muchos españoles, es que nos traigan épocas grises, oscuras, y perdamos aunque sea un ápice de lo que estamos teniendo por culpa de su masividad (y vuelta a empezaaaar). El problema, el mismo. Vienen demasiados como para absorberlos. Y eso implica borrarles cualquier signo de identidad de su pueblo originario. Y ES ESO LO QUE YO CONSIDERO UNA INTEGRACIÓN EN TODA REGLA. [f1/3.01]

Indica Garreta (1996), y se confirma en nuestro estudio, que, dentro de esta caracterización común, se establecen jerarquías y discriminaciones. Los resultados dibujan una escala de mayor a menor discriminación en la que magrebíes y latinoamericanos se sitúan en peores condiciones que los africanos de raza negra. Por otro lado, las «molestias» que genera la presencia de inmigrantes no las "padecen» todos los ciudadanos en igual medida. Las intervenciones insisten en que las capas más desfavorecidas de la población son quienes más «sufren» los «costes» de la inmigración; por el contrario, los residentes en zonas de poder adquisitivo medio y alto apenas notarán su presencia, es más, ellos se benefician de la inmigración porque consiguen trabajadores a bajo precio para sus empresas y hogares. En este punto, racismo y clasismo coinciden:

Por desgracia, vivo en un barrio con muchos magrebíes, y sé de lo que se habla aquí, la gente que no los tiene cerca dicen que hay que ser amables, educados, entenderlos, etc. etc. etc. Yo les digo que si son tan buenos, por qué no se van a vivir en barrios de Barcelona o Madrid que estén llenos de inmigrantes y conviven con ellos. Me gustaría ver lo que aguantan, y veríamos cómo gente que está a favor de ellos se haría RACISTA. [f1/3.11]

Yo vivo en un sitio normal de mi ciudad, un barrio de trabajadores, una zona media, casi en el centro. Hace varios años se ha llenado todo de inmigrantes, ha crecido la delincuencia y los que ya vivíamos allí antes no sabemos cómo huir, sobre todo los que no podemos permitirnos comprar un piso en otro sitio. [f1/2.25]

En términos reales o percibidos, las clases menos favorecidas soportan en mayor medida los "costes» de la inmigración: miedo a la desvalorización de sus viviendas, pequeña delincuencia, degradación de sus barrios, etc. Como indican Pérez Díaz y otros (2001), el discurso humanista que propugna una 
política migratoria permisiva tiene dificultades para diferenciar entre los «ganadores» y los «perdedores» de una determinada política inmigratoria. En la práctica, la tendencia a acentuar los aspectos morales y silenciar los aspectos prácticos comporta una creciente división entre los grupos generadores del discurso y la sociedad en su conjunto, y especialmente con los grupos «perdedores» que, evidentemente, se mostrarán hostiles hacia la inmigración. La tendencia a estigmatizar, desacreditar dichos grupos clasificándolos de racistas o xenófobos acostumbra a tener efectos contraproducentes a corto y medio plazo.

Ahora bien, pese a la proximidad espacial, no existe convivencia: españoles e inmigrantes comparten los mismos espacios, pero no existe una relación de vecindad (confianza, ayuda mutua, etc.). Los motivos aducidos por los autóctonos son las actitudes de los inmigrantes: cuando son minoría, la tendencia al aislamiento y a la formación de guetos donde preservar su identidad; cuando son mayoría, la tendencia a imponer su estilo de vida al conjunto de la población. Es en este momento cuando surge la pugna por el territorio y se plantea la necesidad de "luchar» para evitar sucumbir a la «invasión cultural» que se vislumbra en nuestros barrios y ciudades:

Si en el barrio ya son bastantes, empezarán por la calle, después por la manzana y acabarán convirtiendo el barrio en lo más cercano a su percepción de la sociedad ideal, sometiendo a otros grupos. [f1/1.29]

Como indican Pérez-Díaz y otros (2001), existe la sensación de haber perdido el control de los espacios propios: las calles, las plazas, el territorio habitual. Sienten que su territorio ya no les pertenece, ha sido «ocupado por extraños» que hablan lenguas ininteligibles, son ruidosos, viven hacinados. Y si han sido capaces de «apoderarse» del barrio, pueden ir más lejos, mucho más lejos...

\section{El inmigrante como competidor}

Las visiones que articulan la imagen del inmigrante como competidor centran su atención en dos aspectos: el mercado de trabajo y las prestaciones de bienestar. Pese a que la evidencia empírica lo desmiente, se teme que los inmigrantes desplacen a los autóctonos del mercado laboral, cuanto menos en los segmentos de menor cualificación, y a la vez, que la mayor oferta de trabajo comporte una disminución de los salarios y una mayor precariedad en las condiciones laborales. Paralelamente, se presenta la competencia en el acceso a los recursos de bienestar, y se percibe una cierta discriminación (aparente más que real) de los autóctonos frente a ciertos colectivos de inmigrantes. Veamos de forma más detallada el temor que la inmigración despierta en estos ámbitos:

\section{El cliché de la "competencia por los puestos de trabajo»}

Desde un punto de vista microeconómico, se afirma que un trabajador iniciará el proceso migratorio si las ganancias netas que espera obtener en el país 
de destino superan las previstas en el país de origen. Ahora bien, las expectativas de ingresos se hallan condicionadas por las características del mercado de trabajo y sus posibilidades reales de acceso al mismo. Además, en la decisión de iniciar el proceso migratorio influyen otras variables como la distancia geográfica (que lleva asociado el coste de información) o la existencia previa de concentraciones de inmigrantes del mismo origen, que reduce parte de los riesgos que se asumen al iniciar el proceso migratorio (Martín y otros, 2002).

En cualquier caso, resulta necesario romper con la falsa imagen de que se trata de un grupo laboralmente marginal en sus países de origen o que su nivel de formación es inferior al de la población autóctona, idea errónea que reproducen con frecuencia los discursos de los españoles sobre los extranjeros. El nivel de recursos educativos entre el colectivo de inmigrantes no comunitarios supera la media española. Pese a ello, se concentran en los segmentos ocupacionales menos privilegiados, lo que evidentemente tiene poco que ver con su nivel de formación profesional y mucho con su menor capacidad de negociación y resistencia, pues, como indica Villa (1990), existen categorías parecidas de trabajadores a precios mínimos radicalmente distintos, independientemente de su productividad potencial y/o real. Ahora bien, según Izquierdo (2002), este hecho no les genera frustración, pues centran sus ilusiones en la movilidad intergeneracional, esto es, la esperanza de que cuando sus hijos se incorporen al mercado laboral lo hagan en igualdad de condiciones con la población autóctona. En este sentido, determinados autores consideran que se produce una separación entre «trabajo» e «identidad», lo que permitiría una relación puramente instrumental frente al salario, que facilitaría su adaptación al mercado laboral secundario. De ser ello cierto, la inserción laboral en segmentos ocupacionales con un nivel de estatus inferior a lo que permite su cualificación profesional no resultaría traumática, en la medida que la identidad profesional quedaría substituida por la identidad del grupo, la identidad étnica. Es decir, ante el bloqueo de las trayectorias de movilidad obrera, el inmigrante opta "por recrear espacios y vínculos comunitarios principalmente extralaborales» (De la Haba, 2002: 181). O, como indica Zamora (2001), los inmigrantes viven fuera de la estructura social en la que trabajan y trabajan fuera de la estructura social en la que viven.

Pese a ello, como hemos avanzado, el supuesto conflicto entre trabajadores españoles e inmigrantes se plantea a dos niveles diferenciados. En primer lugar, cuando se les considera competidores directos por puestos de trabajo escasos que también desean ocupar los trabajadores autóctonos:

Tiene razón cuando dice que está el trabajo en España como para darlo a los extranjeros. Que se lo digan a los albañiles, camareros y agricultores españoles que están siendo sustituidos por inmigrantes dispuestos a trabajar por menos y en peores condiciones, aunque la culpa no es de los inmigrantes, sino de los empresarios. [f1/2.15]

Es gracioso, como ya vienen a «lo que sea» con su formación adquirida... ya no se dedican a [...] cuidar ancianos ni a ir a coger patatas..., ahora los podemos 
ver atendiéndote en un banco, en una oficina, de maestros, de taxistas, trabajando en una fábrica, de cocineros..., y esto hace crecer aun más si cabe la dura competencia laboral que ya hay entre jóvenes españoles y que buscan su primer empleo o simplemente quieren trabajar... Entonces se dan cuenta de que no lo pueden hacer por culpa de los inmigrantes... [f1/2.15]

Y, en segundo lugar, cuando se les responsabiliza de la creciente precariedad en las condiciones laborales:

Lo del trabajo que no quieren los españoles, repito que toda la vida los españoles lo han querido hasta que bajaron los salarios. Repito que antes cuando los sueldos eran bajos, los trabajadores de la empresa protestaban, hacían huelgas y los empresarios, como los necesitaban, pues les subían el sueldo y asunto arreglado. Ahora si el sueldo es bajo y los trabajadores hacen huelgas y protestan, no les suben el sueldo, les ponen en la puta calle y contratan inmigrantes a los que sí les parezca bien el sueldo de mierda con tal de agarrarse a cualquier cosa. A mayor oferta de mano de obra, más bajos son los salarios, es la ley de la oferta y la demanda. Antes, cuando un trabajo no lo quería nadie, en lugar de contratar inmigrantes se ofrecía un salario más alto para que fuera más atractivo, ¿entiendes la diferencia? [f1/2.18]

Todo ello nos remite a una cuestión fundamental: el debate sobre la «competencia» o "complementariedad» entre trabajadores autóctonos e inmigrantes. De hecho, los primeros intentos de comprensión teórica de las migraciones se enmarcan en la economía neoclásica y tienen en E. G. Ravenstein, autor de Las leyes de la migración, su precursor. Para él, el factor desencadenante de las migraciones es la existencia de un desajuste entre oferta y demanda de fuerza de trabajo, lo que ocasiona una relación inversamente proporcional entre reserva de fuerza de trabajo y nivel de salario. Así, las migraciones servirían para restablecer el equilibrio entre oferta y demanda de fuerza de trabajo (Zamora, 2001). Por otra parte, las teorías de mercado de trabajo dual (Piore, 1983) señalan que las sociedades generan sistemáticamente una variedad de puestos de trabajo que los autóctonos rechazan realizar, o que sólo aceptan en momentos de especial dificultad. De ahí deriva la necesidad de inmigrantes o, mejor dicho, la necesidad del trabajo de los inmigrantes. Y como afirma Cachón (2002), desde mediados de los ochenta empieza en España un rápido proceso de incremento del «nivel de aceptabilidad» de los trabajadores autóctonos, que se traduce en una repentina demanda de trabajadores inmigrantes para cubrir puestos del mercado de trabajo secundario. Solé y Parella (2001: 31), por ejemplo, señalan que estamos ante «un mercado segmentado, dividido en una serie limitada de esferas o segmentos no competitivos entre sí». En la misma línea, Carrasco (1999: 153) afirma: "Realizando un análisis de conjunto de los trabajadores inmigrantes extracomunitarios en la estructura del mercado laboral español, podemos concluir que no entran en competencia con los trabajadores autóctonos, ya que el propio colectivo de trabajadores inmigrantes extracomunitarios forma un segmento propio del mercado de trabajo». De este 
modo, resultaría falso afirmar que los trabajadores inmigrantes reemplazan a los trabajadores marginales autóctonos:

El que no trabaja en este país es porque no le sale de los cojones. Así de contundente. He pedido gente para ir a trabajar al monte, en condiciones duras, pero bien pagados, a tirar tuberías en medio de la nieve, la lluvia..., y sólo han acudido un senegalés y un marroquí. No ha habido ningún señorito que quisiera acudir, ni a eso, ni a la panadería de mi amigo «porque había que levantarse a las cuatro de la mañana a trabajar».

No hay señoritos que se rebajen a trabajar en las obras, ni en el campo, ni en trabajos que «no están a mi altura universitaria de Magisterio, prefiero opositar, y jolines, es que no sacan plazas».

¿Quién pone mis tuberías? ¿Quién hace el pan? ¿Quién recoge los espárragos? ¿Quién hace nuestras casas? [f1/2.27]

Sin embargo, los debates en los foros de discusión no siempre coinciden con esta afirmación. La tesis subyacente en los discursos críticos indica que, lejos de aumentar el «nivel de aceptabilidad» de la población autóctona, se produce un empeoramiento de las condiciones laborales. Por tanto, no cambian las expectativas (el nivel de aceptabilidad) de la población autóctona, sino las condiciones de los puestos de trabajo a cubrir. En este sentido, se estaría utilizando a la población emigrante como «ejército de reserva» para ejercer una presión a la baja en las demandas de los trabajadores, hasta el punto que algunos empleos dejan de ser atractivos para los autóctonos:

Es la pescadilla que se muerde la cola: los salarios bajan y ya la gente no quiere ese trabajo, por lo que se contrata a inmigrantes. Y, a su vez, los inmigrantes cobran menos y los salarios bajan, con lo que ya los españoles ese trabajo lo quieren menos y se contratan más inmigrantes que piden menos y bajan los sueldos... Y así no salimos del círculo vicioso. [f1/2.16]

Si hay trabajos que los españoles no quieren hacer, es porque están mal pagados y ¿por qué se pagan mal?, por culpa de los empresarios, que los pagan mal precisamente para favorecer eso, que los españoles no quieran esos puestos y poner inmigrantes ilegales pagándoles una miseria. [f1/2.16]

Por todo ello, se plantea la necesidad de hacer frente al dumping social de los inmigrantes, con el fin de evitar la progresiva precarización de las condiciones laborales ${ }^{5}$. Ésta debe ser la línea de acción a seguir por los sindicatos: la defensa de los derechos de los trabajadores autóctonos:

5. «En realidad, cuando se dice que hacen falta inmigrantes, se está diciendo que falta mano de obra barata, lo cual crea inseguridad en grandes sectores de la clase trabajadora, puesto que la existencia de un amplio sector con salarios bajos amenaza a todos los trabajadores, pues presiona los salarios hacia abajo. El argumento que también constantemente se utiliza de que los inmigrantes ocupan los lugares de trabajo que los españoles no desean, ignora que no hay puestos de trabajo intrínsecamente de salario bajo. El empresario tiene dos opciones, o traerse inmigrantes mal pagados o invertir en el puesto de trabajo para aumentar su productividad y pagar mejor salario» (Navarro, 2002: 71). 
¿Cómo es que vienen inmigrantes a trabajar habiendo dos millones de parados españoles?

¡Que poca vergüenza!, la culpa también la tienen los sindicatos, que sólo buscan afiliados, aunque eso sea sacrificar a España. [f2/4.23]

¿No quieren darse cuenta aquéllos que tanto dicen defender al trabajador que este ejército de desesperados, dispuesto a trabajar por una miseria y en condiciones de esclavitud que nos está invadiendo, a lo que conduce es a una reducción de los salarios, a una degradación de las condiciones laborales y a una expulsión de españoles del mercado laboral? [f1/2.16]

De este modo, los inmigrantes, aun siendo víctimas de su necesidad, contribuirían a la estrategia empresarial de reducción de costes salariales y derechos laborales ${ }^{6}$. Con su presencia, se lograría introducir divisiones en el seno de la clase trabajadora y ocultar el conflicto básico entre trabajo y capital, que quedaría sustituido por el enfrentamiento que surge de la competencia —aparente o real- entre trabajadores autóctonos e inmigrantes. En las visiones más radicales, ello responde a la estrategia capitalista (adoptada con la complicidad del Estado) del «divide y vencerás» (Edwards y otros, 1986). De este modo, el «conflicto de clases» queda oculto tras el «conflicto de razas» — «el capitalismo como sistema engendra el racismo», señala Wallerstein (1991: 58)_ y el inmigrante pasa de ser víctima del sistema capitalista global a ser señalado como el responsable (cuando no el culpable directo) de los efectos que el proceso de globalización económica tiene en determinados segmentos ocupacionales.

En otro orden de cosas, la competencia con los trabajadores autóctonos también viene de la mano de la incorporación de los inmigrantes a la economía informal o sumergida. En este punto, Gil (2002: 167) recuerda que «la extensión de la economía sumergida es una característica distintiva de la economía española y una de las variables que más intervienen en las formas de inclusión/exclusión de la población inmigrante» ${ }^{7}$. Se trata de una específica forma de inserción en el mercado que permite la coexistencia de segmentos de «trabajadores privilegiados» y segmentos de «trabajadores precarios». Y, evidentemente, los trabajadores inmigrantes se insertan de manera diferencial en esta estructura dual. Tal constatación, sin embargo, no queda reflejada en los

6. Pese a todo, la evidencia empírica disponible (De New y Simmerman, 1994; Dolado y otros, 1996; González, 2002; etc.) señala que la incidencia de la inmigración en los salarios es escasa. Pese a ello, Weinstein (2002: 246) recuerda que "para la mayoría de los empleadores, la contratación de inmigrantes es un instrumento del que cabe esperar una mejora de los márgenes de beneficio, por lo que apenas hay empleadores que rechacen la libertad de reclutar mano de obra en el extranjero. A menos, pues, que la xenofobia afecte sólo a los trabajadores y no a los empleadores, parece mucho más probable que dicha división sea producto de los intereses económicos divergentes».

7. Según datos de la Comisión Europea, en España la «economía sumergida» representa el $22 \%$ del PIB, lo que proporcionalmente la sitúa en una de las mayores de la UE, con una cuantía que supera los 120.000 millones de euros. 
discursos que responsabilizan a los inmigrantes «irregulares» $\mathrm{o}$ «sin papeles» de la existencia de talleres clandestinos y otras actividades económicas ocultas.

Sin embargo, es incorrecto pensar que la articulación de actividades económicas «ocultas» por parte de empresarios autóctonos (o inmigrados) se activa con el beneplácito de los trabajadores inmigrantes. Otra cuestión distinta es que la presencia de trabajadores inmigrantes con una situación administrativa no regularizada facilite la coincidencia de intereses con los propietarios de talleres clandestinos. Lacomba (2001), por ejemplo, explica que los inmigrantes senegaleses valoran positivamente España e Italia como destinos atractivos, en parte, por la mayor presencia de economía sumergida e informal, lo que facilita su acceso al trabajo aun cuando no disponen de los permisos necesarios. Como afirmaba uno de los participantes en los foros:

Teniendo en cuenta que en España existe mucha economía sumergida que no se declara a hacienda como sucede en la agricultura y en la construcción, pues lógicamente estos sudamericanos es a donde se dirigen a conseguir trabajo y como son muchos y todos compiten entre ellos, el efecto inmediato de un incremento de la oferta de trabajo provoca una reducción del salario. [f2/4.05]

De este modo, y aún cuando se admite que el proceso migratorio se inicia por una situación de necesidad, el discurso dominante se resiste a considerarles víctimas de la discriminación laboral que padecen. Más bien son señalados como culpables por aceptar someterse a tales prácticas y con ello contribuir a la existencia de economía irregular y de los perjuicios que ésta genera en el conjunto de la sociedad. Además, en la medida que se ven obligados a trabajar por debajo de los mínimos establecidos, se afirma que su presencia perjudica a los trabajadores autóctonos e inmigrantes regularizados. Por otro lado, la denominación de «ilegales» con la que se designa a los inmigrantes que no disponen de su documentación en regla (frente a otras menos estigmatizadoras como «irregulares»o «sin papeles») facilita la asociación entre su situación administrativa irregular («ilegal») y la irregularidad («ilegalidad») de las actividades con las que resuelven sus necesidades de subsistencia. En este punto, cabe recordar a Bourdieu $(1988,1991)$ cuando señala que las prácticas clasificatorias tienen efectos sociales en la medida que contribuyen a producir aquello que aparentemente describen.

En todo caso, los participantes en los foros otorgan una importancia menor a la que en principio cabría prever a la distinción entre inmigrantes «legales»e «ilegales», que queda sustituida por otra mucho más contundente: la distinción entre los que "vienen a trabajar» y los que "vienen a aprovecharse», es decir, aquéllos que no desean resolver su necesidades mediante la incorporación al mercado laboral, lo que nos remite necesariamente a la cuestión de la inseguridad y la delincuencia («el inmigrante como amenaza») y al uso fraudulento y/o abusivo de los recursos de bienestar («el inmigrante como competidor»).

No pretendemos extendernos en el primero de los aspectos señalados, pues consideramos que muchos de los argumentos planteados en el apartado ante- 
rior deberían ser reproducidos, por ello nos limitamos a señalar la tendencia a considerar que la inseguridad ciudadana se incrementa de modo significativo con la llegada «incontrolada» de inmigrantes, y que ello se explica, en buena parte, recurriendo a argumentos de tipo culturalista, según los cuales nuestro sistema legal se adaptaría bien al universo cultural de un occidental, pero resultaría excesivamente laxo para personas que provienen de universos culturales distintos al nuestro. Por otro lado, los análisis sociológicos enfatizan los factores ambientales externos al proceso de desviación (Garreta, 1996), de este modo, los inmigrantes sufrirían un conflicto anómico fruto del contraste entre estilos de vida, sistemas de creencias y valores, en suma, sistemas culturales opuestos e incompatibles.

En Sudamérica ¿̨tienen tantas contemplaciones con los delincuentes? [f2/4.18]

Como veremos a continuación, similares argumentos de tipo culturalista pueden extraerse del análisis de los comentarios que los participantes en los foros realizan cuando se aborda la cuestión de uso (o abuso) de los recursos de bienestar por parte de la población inmigrante.

\section{El cliché de la "competencia por los recursos de bienestar»}

La supuesta competencia entre autóctonos e inmigrantes no sólo se plantea en el ámbito del mercado de trabajo, también se presenta, y si cabe de forma más evidente, en el acceso a los recursos de bienestar. La llegada de trabajadores inmigrantes supone un incremento de los ingresos públicos en la medida que están sujetos a los mismos impuestos y contribuciones sociales que la población autóctona. Paralelamente, también comporta un incremento del gasto público por su participación en el consumo de los recursos de bienestar - educación, sanidad, vivienda, pensiones, prestaciones por desempleo, etc.- a los que tienen derecho en igualdad de condiciones que los nacionales. En cualquier caso, la mayoría de estudios empíricos indican que la relación entre ingresos y gastos que origina la presencia de inmigrantes se salda con un balance positivo (Weber y Straubhaar, 1994).

Por otro lado, los argumentos demográficos son esgrimidos con cierta frecuencia para insistir en la necesidad que tiene el Estado español de trabajadores inmigrantes: las bajas tasas de fertilidad y la mayor esperanza de vida provocan la desaceleración del crecimiento vegetativo y el envejecimiento de la población. Ello comporta que aumenten los perceptores de determinadas prestaciones sociales (pensiones, sanidad, etc.) y que se deba incrementar la presión fiscal con el fin de garantizar la viabilidad del sistema. La presencia de trabajadores inmigrantes jóvenes (junto con la mayor tasa de fertilidad que muestra este colectivo) puede contribuir a resolver el desequilibrio. Esta línea argumental queda recogida en los debates en los foros, y se señala como uno de los aspectos positivos de la inmigración.

[...] lo que indican los estudios demográficos es un envejecimiento de la población que puede ser atenuado por la inmigración. [f4/3.07] 
Pero, como era de esperar, no todos coinciden:

Y déjense ya de demagogias de que nos pagarán las pensiones y tal y cual, porque ese rollo ya no se lo cree casi nadie. Ya la gente no pica, los que no se lo han creído nunca siguen sin creérselo, y los que antes se lo creían (yo antes también me lo creía) se convencen y dejan de creérselo. [f1/3.05]

[...] que tenemos una tasa de natalidad más baja del mundo y que esto provocará la quiebra de la seguridad social y no se podrán mantener las pensiones de los jubilados en el futuro debido a la falta de contribuyentes a la seguridad social entonces que me explique [...] cómo van a contribuir los inmigrantes a esto si trabajan casi todos en economía sumergida sin cotizar. [f3/4.05]

Como explican Martín y otros (2002), garantizar el sistema de pensiones mediante el recurso a la inmigración requeriría generar enormes flujos migratorios, que podría desembocar en tensiones sociales. Según estimaciones de las Naciones Unidas (2000), el Estado español tendría que acoger aproximadamente 240.000 inmigrantes anualmente hasta el 2050. Por otro lado, resulta evidente que, llegado el momento, los inmigrantes pasarán a engrosar las filas de receptores de una pensión, por lo que su presencia contribuye a retardar y a suavizar el problema, pero no a resolverlo definitivamente.

Ahora bien, más allá de estimaciones sobre beneficios y costes de la inmigración, los participantes sostienen (como una verdad evidente) que la presencia de inmigrantes dificulta el acceso de los autóctonos a las prestaciones sociales y a los recursos de bienestar. En palabras de Gaviria (1992: 134), «la llegada de extranjeros legales o clandestinos, supone un incremento en la competencia por la captación de los recursos destinados a los estratos más bajos de la sociedad española». Por tanto, la primera cuestión que se plantea es: ¿¿deben tener derecho a las prestaciones sociales en las mismas condiciones que los españoles? Desde las visiones más humanistas, que reclaman una mínima cobertura social para todos los seres humanos, se pasa a las que ven en el acceso a las prestaciones sociales una garantía para la integración social de los inmigrantes (y con ello una garantía de estabilidad y cohesión social), hasta llegar a las que rechazan el reconocimiento de cualquier derecho en el acceso a las prestaciones de bienestar.

Las intervenciones que sostienen esta última postura parten de dos argumentos distintos: en primer lugar, se señala la existencia (no de personas, sino) de colectivos de inmigrantes que no desean resolver sus problemas mediante la incorporación al trabajo y, en segundo lugar, se proclama la subordinación de los derechos de los inmigrantes a los derechos de los autóctonos. Según las primeras, el proceso migratorio se inicia por la voluntad de aprovecharse del mayor desarrollo de las instituciones de bienestar en nuestro país. Por tanto, no las mayores oportunidades de incorporación al trabajo, sino las mayores posibilidades de subsistir al margen de éste es el elemento desencadenante del proceso migratorio. En este punto, cabe recordar las palabras de Azurmendi 
(2001), cuando afirma: «El inmigrante no sólo no viene de una cultura del trabajo, sino de una que podríamos simplificar como más próxima al ocio, pues, por muy diferentes que sean entre sí las diversas sociedades jerarquizadas parentalmente desde Marruecos hasta la costa guineana del África atlántica, todas poseen el rasgo común de privilegiar solamente el trabajo en cuanto es suficiente para adquirir el sustento diario». En cualquier caso, los distintos colectivos de inmigrantes (africanos, árabes y latinoamericanos) son estigmatizados de forma muy distinta y, sin duda, el colectivo que levanta más «sospechas» es, sorprendentemente ${ }^{8}$, el colectivo latinoamericano:

Los sudamericanos son los únicos inmigrantes que vienen a España a chupar del bote con la excusa de que sus países están mal (están mal porque ellos son unos vagos y quieren que trabaje el prójimo). [f2/4.15]

En todo caso, este tipo de planteamientos no aporta nada nuevo, sencillamente reproducen los discursos neoliberales sobre los efectos perversos de los programas de bienestar social, adaptándolos al colectivo inmigrante: «las personas deben resolver sus necesidades mediante su incorporación al trabajo»; "cualquier sistema de bienestar, en la medida que permite subsistir al margen del trabajo, perjudica más que beneficia a sus receptores y dificulta el funcionamiento eficiente del sistema económico»; etc. (Morell, 2002).

Como ya hemos avanzado, un segundo grupo de argumentos insiste en la idea que se establece una competencia por recursos escasos y limitados, y se reclama la prioridad de derechos para los autóctonos. De este modo, la construcción de la identidad (nosotros) y de la alteridad (los otros) supone un proceso de jerarquización en el que entran en juego conflictos de intereses acerca del acceso a los recursos sociales. Se trata, en suma, de estrategias simbólicas de legitimación de un determinado statu quo (Lucas, 2002) o, en términos de Bourdieu (1988, 1991), la "estrategia de sociodiceas»:

¿Y por qué un inmigrante tiene los mismos derechos de sanidad, educación, vivienda, etc. que un español si el español lleva aportando al Estado toda la vida y el inmigrante no lo ha hecho nunca (o quizá poco tiempo)? [f1/2.28]

Según la «lógica de naturalización del Estado nación», el Estado tiene la obligación de garantizar los derechos legales, económicos y sociales de la población autóctona, pero tales derechos no pueden extrapolarse en toda su extensión a los inmigrantes. Esta premisa les remite a una posición de subordinación en el acceso a los recursos de bienestar:

8. Sorprendentemente en la medida que, como hemos visto, determinados participantes tienden a señalar que las afinidades culturales entre latinoamericanos y españoles son superiores a las de otros colectivos de inmigrantes, lo que debería facilitar su integración en la sociedad española. 
A molestar a su casa, que ya tenemos bastante con nuestros hijos tontos. Te repito, es cuestión de sentido y pragmatismo ¿Para qué se hacen entonces los países si no defienden ni representan los intereses de un colectivo de personas? [f1/3.03]

De este modo, se acepta que los inmigrantes son un colectivo necesitado de atención en aras de lograr su plena integración social, pero a la vez se establece una jerarquía casi inconsciente que los sitúa por debajo de los autóctonos. Evidentemente, este tipo de discursos delimitan «los extranjeros» a los inmigrantes pobres, por oposición a aquéllos que proceden de países económicamente más desarrollados, que, en este ámbito, quedan eliminados de los discursos. El problema, por tanto, no es ser inmigrante, sino ser pobre además de inmigrante. Ellos son quienes, con su presencia, empobrecen al conjunto de la sociedad y ponen en peligro nuestro nivel de bienestar.

Los contribuyentes españoles no tenemos la obligación de integrar con nuestros impuestos a todos los inmigrantes que vienen. Y menos cuando hay millones de compatriotas necesitados de empleo y vivienda. Precisamente esa posibilidad de recibir ayudas es otro motivo adicional que les impulsa a venir. [f1/1.18]

Así, los extranjeros procedentes de países económicamente más desarrollados (jubilados del norte de Europa, profesionales de empresas extranjeras con inversiones en el Estado español, etc.) son bien recibidos en la medida que nos aproximan a nuestro ideal de bienestar. Paralelamente, aquéllos que proceden de zonas económicamente menos desarrolladas son vistos como una carga que reduce nuestro nivel de bienestar por el consumo de recursos que realizan: «los primeros son la representación de nuestro acceso (posible) al mundo de la abundancia y el progreso; los segundos nos retrotraen al retraso y la pobreza» (Colectivo Ioé, 1995: 89).

El problema no es la inmigración, el problema es la pobreza, con la pobreza viene la marginación, se soporta mal el espectáculo de la pobreza, no es agradable... Al pobre, al mendigo, al desarraigado no se le soporta... [f1/301]

Pero, además, existe la idea generalizada que los inmigrantes están sobreprotegidos, que gozan de más derechos que la población autóctona. En parte, porque el Estado español no dispone de un Estado de bienestar desarrollado ni del nivel de prestaciones que existen en otros países europeos, lo que genera una gran presión social en el segmento de población autóctona en situación precaria. Se experimenta, de este modo, un "agravio comparativo», basado en la idea de que mientras los autóctonos han de trabajar duramente para resolver sus necesidades (en ocasiones insuficientemente), los inmigrantes acceden fácilmente a las prestaciones sociales de las administraciones públicas y las ONG. Esto se concreta (no en el uso, sino) en el abuso de los recursos de bie- 
nestar ${ }^{9}$, en detrimento de la población autóctona precarizada. En los foros se reproducen numerosos ejemplos de esta forma de pensar, de los cuales mostramos dos ejemplos:

[...] Pues bien, aun teniendo esta situación de falta de ingresos, llevo dos años solicitando cada curso la beca para los libros de texto y demás y NO ME LA DAN PORQUE NO SOY LO BASTANTE POBRE. Pero me encuentro con que al lado mío llega un sudaca y simplemente le piden el pasaporte de su país (ni siquiera la tarjeta de residencia para comprobar si es legal, ique va!) y le dan los libros sin más explicaciones. Me quejo y me dicen que los inmigrantes tienen prioridad a la hora de optar a esas becas, que simplemente por ser inmigrantes tienen ese derecho sin tener que demostrar sus ingresos. [f2/4.06]

Resulta que se les concede un subsidio (tipo desempleo) a los inmigrantes que hayan tenido abuelos españoles [...] Me parece abusivo este tipo de subsidios que se les conceden a los inmigrantes en España. Ya que resulta que aquí todos los españoles cotizando como burros, y llega el listo de turno inmigrante que no ha trabajado jamás en España y van y le dan una pasta durante bastantes meses [...] Esto ya pasa de rosca, cuando en España hay miles de personas que se les ha agotado la prestación por desempleo (en la mayoría de casos cuatro meses de prestación), continúan sin empleo, y sin cobrar un duro. Y nadie les ayuda, a pesar de haber estado cotizando toda su vida. Esto es lo que nos traen los inmigrantes a España. ¿O acaso a esto no se le llama ROBO? [f2/4.05]

En definitiva, la presión que siente (o se atribuye a) parte de la población autóctona por la escasez de prestaciones sociales, fruto del incompleto desarrollo del Estado de bienestar en España (Navarro, 2002), no se concreta en demandas de un incremento del nivel de gasto social, sino en señalar al inmigrante como el culpable de las dificultades de acceso a las prestaciones sociales y de la situación de inseguridad económica y social que afecta a determinados sectores de las capas medias de la población. En palabras del colectivo Ioé (1995: 74), «la quiebra del modelo desarrollista pone en cuestión el futuro de los hijos, los retiene en la casa paterna, bloqueando las expectativas familiares de progreso. Esta situación se percibe como un proceso inevitable, lo que alimenta los argumentos excluyentes hacia los extranjeros; en tanto no se clarifique la propia situación, su presencia no es de recibo".

9. Gil (2002: 12) sintetiza este tipo de opiniones en los siguientes términos: «Otra particularidad que condiciona la vida de los inmigrantes africanos es su opción por enviar todo el dinero a sus familias; de no ser así, podrían vivir con más dignidad de la que tienen». En otras palabras, el inmigrante elige vivir de manera mísera y luego, reclamando el derecho y la justicia, se aprovecha de la ayuda social. 


\section{A modo de conclusión}

El conocimiento que tenemos del «otro» es sumamente superficial, limitado, confuso, cargado de prejuicios culturales. La imagen del inmigrante se halla distorsionada por una serie de estereotipos que dificultan enormemente la convivencia. Ello explica, por ejemplo, la tendencia (real o atribuida) a la creación de guetos en los que preservar su identidad. La población autóctona interpreta el repliegue comunitario como prueba de la nula voluntad de integración de las minorías. Sin embargo, la formación de comunidades étnicas solidarias también puede responder a la necesidad de autoprotegerse de un contexto (que es o consideran) hostil (Samper, 2003).

Además, la convivencia entre ambos colectivos resulta difícil, incluso imposible, cuando se asigna al colectivo inmigrante unos atributos culturales que se señalan como incompatibles con los autóctonos. En este punto, la anomía derivada de la colisión normativa explicaría la falta de integración: orientan su vida en función de un sistema de valores incompatibles con nuestro sistema social. Dicha explicación sirve tanto cuando se aborda la cuestión de la delincuencia (que en los autóctonos se explica como una "anomalía» o "desviación" y en los inmigrantes como una cuestión cultural: «el sistema de justicia occidental es demasiado relajado para la cosmovisión de algunos colectivos de inmigrantes»), la incorporación al mundo del trabajo asalariado («no vienen de una cultura del trabajo») o el acceso a los recursos de bienestar («no son previsores", "no tienen ética del trabajo", "prefieren malvivir de las ayuda sociales», "son vagos», etc.). La tesis de la incompatibilidad cultural se complementa con el «supuesto esencialista», que sostiene que los universos culturales (autóctono y alógenos) son esencialmente inamovibles y no modificables en sus rasgos fundamentales. De este modo, la integración de los inmigrantes en la sociedad de acogida deviene prácticamente imposible.

Como afirma el Colectivo Ioé (1995:83), la representación por antonomasia de que existen incompatibilidades culturales irresolubles es la minoría gitana. La falta de integración de este colectivo se explica por la persistencia de sus particularidades culturales, y ello no aporta en modo alguno riqueza al conjunto de la sociedad. Por el contrario, genera conflictividad social: «no existen posibilidades de mutuo intercambio y convivencia fructífera cuando la minoría es (o sea, se la caracteriza como) portadora de tradicionalismo cerrado, irracionalidad, y agresividad». De este modo, la única integración posible (esto es, la única aceptada) pasa por renunciar a sus rasgos culturales particulares y diluirse en la «normalidad» dominante. Pero, en cualquier caso, «si después de siglos los gitanos españoles continúan sin "normalizarse", estamos ante la prueba de que la llegada de extranjeros provenientes de culturas "extrañas" no aportaría más que problemas irresolubles a la sociedad autóctona». En nuestra opinión, este tipo de planteamientos constituyen un grave error en la medida que ignora la dimensión dialéctica de las culturas: «Presentando la cultura de este modo se pierde de vista que las culturas adquieren su sentido en el contexto en que se ubican, que son dinámicas, cambian- 
tes por definición y rara vez tan homogéneas como se las ve desde fuera» (Samper, 2003: 5).

En cualquier caso, los estereotipos asignados a los distintos colectivos de inmigrantes varían significativamente, y como hemos visto, el nivel de desarrollo socioeconómico constituye un factor determinante. Se establece una jerarquía en función de la "proximidad» o «alejamiento» (atribuido) de la cultura de origen del inmigrante con las normas y los valores dominantes en la sociedad de acogida, pero, a la vez, el nivel de desarrollo económico de la sociedad de origen del inmigrante deviene clave en la determinación de la distancia cultural percibida. Así, cuanto menor sea el grado de desarrollo económico de la sociedad de origen del inmigrante y mayor la distancia cultural percibida, mayores serán las actitudes de rechazo y las dificultades de integración. En este proceso intervienen categorías como el origen, el aspecto, los objetivos económicos del grupo o las propiedades personales que modelan la percepción de la sociedad respecto a los grupos minoritarios. Además, si el grupo minoritario es numeroso (o se percibe como tal), la valoración será mucho más negativa (Garreta, 1996).

Sin duda, el colectivo de origen árabe es quien debe afrontar una situación más compleja, pues aparece diferenciado en términos culturales, religiosos y lingüísticos. Pero, además, la representación occidental del mundo islámico se encuentra condicionada por una serie de estereotipos negativos que lo identifican con el terrorismo, el fanatismo, el fundamentalismo, el machismo..., en definitiva, la amenaza islámica, que se concreta en la voluntad de invadir nuevos territorios. Como afirmaba uno de los participantes en los foros:

Hay países que aleccionan en las escuelas que España les pertenece. Que fueron injustamente expulsados. Que hay que recuperar lo que es suyo. [f1/2.09]

En el extremo opuesto se situarían los europeos y norteamericanos que (como nosotros) son blancos, cristianos, occidentales, avanzados, en suma, son la encarnación de la modernidad. De este modo, se enfrenta «modernidad» a «premodernidad», «civilización» a «barbarie». Y, como afirma Santamaría (2002: 60) «no daremos cuenta exacta de las evocaciones que conllevan los términos bárbaro y barbarie si nos quedamos en señalar la diferencia e incluso la desigualdad de desarrollo cultural y no señalamos además que, opuestos y complementarios a los de civilizado y civilización, significan también un cierto atraso o degeneración moral, con sus insinuaciones de incivilidad, grosería, crueldad, brutalidad o villanía, en suma, de gobierno de la fuerza y de la irracionalidad que asedia o acosa a los moradores de la modernidad».

En cualquier caso, cabe resaltar que no todos los sectores sociales asumen en igual medida las externalidades (positiva y negativas) de la inmigración. Y si, como afirma Weinstein (2002), los trabajadores nativos no son de por sí ni más ni menos miopes que los empleadores nativos, parece razonable pensar que la división de opiniones en torno a la inmigración es el producto de intereses económicos divergentes. Unos esperan incrementar el margen de beneficios, 
otros temen que sus intereses se vean perjudicados. Y más allá de que las expectativas de unos y otros se confirmen o se desmientan, los discursos de la inmigración se utilizarán como armas simbólicas con el fin de imponer una visión del mundo coherente con sus intereses de clase, esto es, con la voluntad de maximizar sus posiciones de poder. Por tanto, hay que remitir el discurso sobre la inmigración a los procesos y conflictos sociales reales de la situación histórica que lo engendra y lo configura.

\section{Bibliografía}

Azurmendi, M. (2001). «Inmigración y conflicto en El Ejido». Claves de la Razón Práctica, núm. 116.

Bourdieu, P. (1988). Cosas dichas. Barcelona: Gedisa.

- (1991). El sentido práctico. Madrid: Taurus.

CACHÓN, L. (2002). «La formación de la "España inmigrante": mercado y ciudadanía». REIS, núm. 97.

CALVO, T. (1990). El racismo que viene. Madrid: Tecnos.

CARRASCO, C. (1999). Mercados de trabajo: Los inmigrantes económicos. Madrid: IMSERSO.

Colectivo IOÉ (1994). «La inmigración extranjera en España: sus características diferenciales en el contexto europeo». En CONTRERAS, J. (comp.). Los retos de la inmigración. Racismo y pluriculturalidad. Madrid: Talasa.

- (1995). Discursos de los españoles sobre los extranjeros. Madrid: CIS.

- (2002). «Migraciones internacionales: entre el capitalismo global y la jerarquización de los Estados». En Clavijo, C.; Aguirre, M. (eds.). Políticas sociales y Estado de bienestar en España: las migraciones. Madrid: Fundación Hogar del Empleado.

Comisión Especial sobre la InMigración y la EXTRANJería del Senado (2002). Comparecencia del profesor de la Universidad del Pais Vasco, Don Mikel Arzumendi Inchausti, para que informe en relación con la materia objeto de estudio de la comisión. (713/000450), sesión celebrada el 18 de febrero de 2002.

Dolado, J. J.; Jimeno, J. F.; DuCE, R. (1996). «The effects of migration on the relative demand of skilled vs. Unskilled labour, evidence from Spain». Discussion Papers, núm. 906. Center for Economic Policy Research.

Donati, P. (2002). «Ciudadanía y sociedad civil: dos paradigmas». REIS, núm. 98, p. 37-64.

EDWARDS, R.; GORDON, D.; REICH, J. M. (1986). Trabajo segmentado, trabajadores divididos. Madrid: MTSS.

GALlisot, R. (1985). Misère de l'antiracisme. París: L'Arcantère.

GARRETA, J. (1996). «Inmigración, desviación social y delito. Inmigrantes marginados e inmigrantes delincuentes». En SolÉ, C. (ed.). Racismo, etnicidad y educación intercultural. Lleida: Universitat de Lleida. Colección Educació i Món Actual, 4.

- (2000). «Inmigrantes musulmanes en Cataluña». Revista Internacional de Sociología, núm. 25.

- (2002). «Inmigrantes musulmanes en una sociedad "laica". Procesos de creación, consolidación y retos de futuro de las mezquitas». Papers, núm. 66, p. 249-268.

GAVIRIA, M. (1992). «La contradicción entre los precarizados y los excluidos españoles y los inmigrantes económicos». Alfoz, núm. 91-92. 
GIL, S. (2002). «Políticas públicas como tecnologías de gobierno. Las políticas de inmigrantes y las figuras de la inmigración». En Clavijo, C.; Aguirre, M. (eds.). Políticas sociales y Estado de bienestar en España: las migraciones. Madrid: Fundación Hogar del Empleado.

GonZÁLEZ, A. (2002). «Efectos macroeconómicos de la inmigración. Impacto sobre el empleo y los salarios de los nativos». Papers, núm. 66, p. 133-153.

HABA, J. de la (2002). «Trabajadores inmigrantes y acción colectiva: una panorámica sobre las relaciones entre inmigrantes y sindicalismo en Europa». Papers, núm. 66, p. 155-186.

IZQUIERDO, A. (2002). «La educación errante». En La sociedad. Teoría e investigación empirica. Madrid: CIS.

LACOMBA, J. (2001). «Inmigrantes senegaleses, islam y cofradías». Revista Internacional de Sociología, núm. 29.

LuCAS, J. (2002). "Cultura, inmigración y Estado». En Clavijo, C.; Aguirre, M. (eds.). Politicas sociales y Estado de bienestar en España: las migraciones. Madrid: Fundación Hogar del Empleado.

MarTín, C. y otros (2002). L'ampliació de la UE. Efectes sobre l'economia. Barcelona: La Caixa. Col-lecció d'Estudis Econòmics, 27.

MaYANS, J. (2002). Genero chat, o cómo la etnografía puso un pie en el ciberespacio. Barcelona: Gedisa.

MORALES, J.F.; PÁEZ, D. (1996). «Estereotipos, discriminación y relaciones intergrupos en España y Latinoamérica». En BourChIS R.V.; LEYENS, J.P. (comps.). Estereotípos, discriminación y relaciones entre grupos. Madrid: McGraw-Hill.

Morell, A. (2002). La legitimación social de la pobreza. Barcelona: Anthropos.

NACIONES UNIDAS (2000). Replacement migration. Is it a solution to declining and ageing populations? Nueva York: Department of economics and Social Affairs.

NAVARRO, V. (2002). Bienestar insuficiente, democracia incompleta. Barcelona: Anagrama.

NEW, J.P. de; SimMERMAN, K.F. (1994). "Blue collar labour vulnerability, wage impacts of migration». En STEINMANN, G.; UlRICH, R. (eds.). Economic consequences of immigration to Germany. Heidelberg: Physica-Verlag.

Pérez-Díaz, V.; Álvarez-Miranda, B.; GonZÁlez, C. (2001). Espanya danvant la inmigració. Barcelona: La Caixa. Col-lecció d'Estudis Socials, 8.

Piore, M. (1983). «Los trabajadores extranjeros». En Paro e inflación. Perspectivas institucionales y estructurales. Madrid: Alianza.

PNUD (2002). Arab human development. Repor 2002. Nueva York: U.N. Public. SAMPER, S. (2003). «Contradicciones y funciones del discurso culturalista: el caso de las mujeres marroquíes en España». En IV Congrés Català de Sociología (comunicaciones), Reus. Disponible en http:// www.iecat.netlacs

SANTAMARÍA, E. (2002). «Inmigración y barbarie. La construcción social y política del inmigrante como amenaza», Papers, núm. 66, p. 59-75.

SARTORI, G. (2001). La sociedad multiétnica. Madrid: Taurus.

SOLÉ, C. (1995). Discriminación racial en el mercado de trabajo. Madrid: CES.

SolÉ, C.; PARella, S. (2001). "La inserción de los inmigrantes en el mercado de trabajo. El caso español». En SOlÉ, C. (coord.). El impacto de la inmigración en la economía y en la sociedad receptora. Barcelona: Anthropos.

TERRÉN, E. (2002). «La etnicidad y sus formas: aproximación a un modelo complejo de la pertenencia étnica», Papers, núm. 66, p. 45-57.

TURKLE, (1997). La vida en la pantalla: la construcción de la identidad en la era internet. Barcelona: Paidós. 
VAlLES, M.S.; CEA, M.A.; IZQUIERdO, A. (1999). Las encuestas sobre inmigración en España y Europa. Madrid: Ministerio de Trabajo y Asuntos Sociales. Colección Observatorio Permanente de la Inmigración, 3.

VILLA, P. (1990). La estructuración de los mercados de trabajo. Madrid: MTSS.

WALLERSTEIN, I. (1991). «Universalismo, racismo y sexismo, tensiones ideológicas del capitalismo». En WALLERSTEIN, I.; BALIBAR, E.: Raza, nación y clase. Madrid: Iepala.

Weber, R.; StraubHaAR, T. (1994). «Budget incidence of immigration into Switzerland. A cross section analysis of the public transfer system». En Discussion Papers, núm. 934. Center for Economic Policy Research.

Weinstein, E. (2002). «Hacia el nuevo paradigma de la inmigración beneficiosa para todos». Revista Internacional del Trabajo, vol. 121, núm 3.

Zamora, J.A. (2001). «Migraciones en un mundo globalizado». Iglesia Viva, 205. 